Cellular Physiology
and Biochemistry and Biochemistry Published online: March 04,2016

Accepted: December 11, 2015

This article is licensed under the Creative Commons Attribution-NonCommercial-NoDerivatives 4.0 International License (CC BY-NC-ND) (http://www.karger.com/Services/OpenAccessLicense). Usage and distribution for commercial purposes as well as any distribution of modified material requires written permission.

\title{
MicroRNA-3666 Regulates Thyroid Carcinoma Cell Proliferation via MET
}

\author{
Gang Wang Chengzhong Cai Lei Chen \\ Department of General Surgery, the Tenth People's Hospital, Tongji University, Shanghai, China
}

\section{Key Words}

Thyroid carcinoma (TC) • MiR-3666 • MicroRNAs (miRNAs) • Cancer cell proliferation • Cancer cell apoptosis $\cdot$ MET (hepatocyte growth factor receptor)

\begin{abstract}
Background/Aims: Thyroid carcinoma (TC) is a highly lethal malignant cancer and its carcinogenesis remains undetermined. Dysregulation of microRNAs (miRNAs) is well known to be involved in the development of various cancers, including TC, whereas a role of miR-3666 in the pathogenesis of TC has not been appreciated. Methods: We analyzed the levels of MET and miR-3666 in TC tissue and the relationship of miR-3666 levels with patients' prognosis. We then overexpressed miR-3666 by miRNA mimics transfection and inhibited miR-3666 by miRNA antisense transfection in TC cells. Cell survival and growth were analyzed by CCK- 8 assay and MTT assay, respectively. Cell apoptosis and proliferation were analyzed by flow cytometry. Bioinformatics analyses were applied to predict miR-3666 targets, which was then confirmed using luciferase reporter assay. Results: We detected significantly higher levels of MET, and significantly lower levels of miR-3666 in TC tissue, compared to the adjacent nontumor tissue. Moreover, the low miR-3666 levels were associated with poor survival of the patients. Overexpression of miR-3666 significantly inhibited cell growth, while depletion of miR-3666 increased cell growth in TC cells. Moreover, the effects of miR-3666 on cell growth appeared to result from alteration in cell proliferation, rather than changes in cell apoptosis. MiR-3666 was found to bind to the 3'-UTR of MET mRNA to inhibit its translation in TC cells. Conclusion: Reduced miR-3666 levels in TC tissue may promotes TC growth, possibly through MET-mediated cell proliferation.

(C) 2016 The Author(s)

Published by S. Karger AG, Basel
\end{abstract}

\section{Introduction}

About 80\% diagnosed thyroid carcinoma (TC) are the papillary carcinoma [1]. Although TC may occur in childhood, it is mainly seen in adults of middle age and has a higher incidence in women than in men [2]. The prognosis of TC is poor, largely resulting from the insufficient knowledge of regulation of cancer growth [3-6]. Therefore, understanding 


\section{Cellular Physiology Cell Physiol Biochem 2016;38:1030-1039 and Biochemistry Published online: March 04, $2016 \quad$\begin{tabular}{l|l} 
DO 2016 The Author(s). Published by S. Karger AG, Basel \\
www.karger.com/cpb
\end{tabular} \\ Wang/Cai/Chen: MiR-3666 Inhibits TC Growth via MET}

the molecular mechanisms underlying the tumorigenesis and tumor progression of $\mathrm{TC}$ is extremely important.

MET is an oncogene protein with tyrosine kinase activity, and is also known as hepatocyte growth factor receptor (HGFR) [7], which is a unique receptor for mitogenic factor HGF [8]. After protein translation, the primary single chain MET precursor is cleaved to form alpha and beta subunits, which reunite to form the mature receptor through disulfide molecules [8]. However, the regulation of MET protein translation is not completely understood. Met is predominantly expressed by epithelial cells and is activated by HGF to transduce signals related to mitosis. MET plays a critical role during embryogenesis and tissue repair in adults [8], and abnormal activation of MET has been detected in various cancers [9-14], including TC $[15,16]$. However, how MET is regulated in TC remains unclear.

MicroRNA (miRNA) is a group of non-coding small RNAs of about 22 nucleotides, and has been found to regulate more than expression of one third of the genes posttranscriptionally, through its base-pairing with the $3^{\prime}$-untranslated region (3'-UTR) of target mRNA $[17,18]$. Cancer initiation and progression have been associated with abnormal expression of some miRNAs [19-21]. MicroRNA (miRNA) is a class of non-coding small RNA that specifically recognizes the $3^{\prime}$-untranslated region (3'-UTR) of the mRNA of some genes through nucleotide pairing $[17,18]$. MiRNAs play a critical role in cancinogenesis of various tumors [19-21], as either tumor suppressor or enhancer. Among all miRNAs, miR-3666 has been rarely studied and reports on its involvement in cancer are lacking.

Here, we analyzed the levels of MET and miR-3666 in TC tissues, and studied the association of miR-3666 with prognosis of the patients. We then overexpressed miR-3666 or inhibited miR-3666 in 2 TC cell lines and studied their effects on MET, cancer cell growth, survival, apoptosis and proliferation.

\section{Materials and Methods}

\section{Patient specimen}

Surgical specimens from 25 TC patients and matched tumor-adjacent normal thyroid tissues (NT) were obtained postoperatively in the Tenth People's Hospital of Tongji University from 2009 to 2013. All patients gave signed, informed consent for the tissue to be used for scientific research. Ethical approval for the study was obtained from the Tenth People's Hospital of Tongji University. All diagnoses were based on pathological and/or cytological evidence. The histological features of the specimens were evaluated by senior pathologists according to the World Health Organization classification criteria. All patients had been followed-up for 30 months. Complete clinical data was electronically recorded.

\section{Cell line culture and transfection}

TT is a human thyroid carcinoma line [22] purchased from ATCC (American Type Culture Collection, Manassas, VA, USA), and has been widely used in TC research. PTC is another commonly used human thyroid carcinoma line [23]. Both cell lines were cultured in in RPMI1640 medium (Invitrogen, Carlsbad, CA, USA) supplemented with 15\% fetal bovine serum (FBS; Sigma-Aldrich, St Louis, MO, USA) in a humidified chamber with $5 \% \mathrm{CO}_{2}$ at $37^{\circ} \mathrm{C}$. MiRNAs mimics (miR-3666) and miRNAs antisense oligonucleotides (asmiR-3666) were obtained from Origene (Beijing, China). A null sequence was used as a control (null). The plasmids were transfected into cells at a concentration of $50 \mathrm{nmol} / \mathrm{l}$ using Lipofectamine 2000, according to the manufacturer's instructions (Invitrogen).

MiRNA target prediction and 3'-UTR luciferase-reporter assay

MiRNAs targets were predicted as has been described before, using the algorithms TargetSan (https:// www.targetscan.org) [24]. The MET 3'-UTR reporter plasmid (pRL-MET) and the MET 3'-UTR reporter plasmid with a mutant at miR-3666 binding site (pRL-MET-mut) were purchased from Creative Biogene (Shirley, NY, USA). TT cells were co-transfected with pRL-MET/pRL-MET-mut and miR-3666/as-miR-3666/ null by Lipofectamine 2000 ( $5 \times 10^{4}$ cells per well). Cells were collected 48 hours after transfection for assay using the dual-luciferase reporter assay system gene assay kit (Promega), according to the manufacturer's instructions. 


\section{Cellular Physiology Cell Physiol Biochem 2016;38:1030-1039

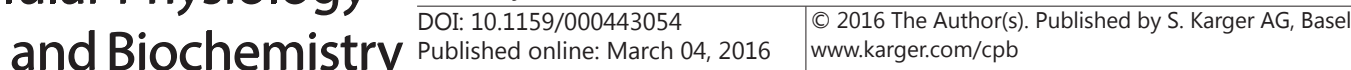 \\ Wang/Cai/Chen: MiR-3666 Inhibits TC Growth via MET}

\section{Quantitative RT-PCR (RT-qPCR)}

Total RNA was extracted from resected specimens or from cultured cells with miRNeasy mini kit (Qiagen, Hilden, Germany). Complementary DNA (cDNA) was randomly primed from $2 \mu \mathrm{g}$ of total RNA using the Omniscript reverse transcription kit (Qiagen). Quantitative PCR (RT-qPCR) were performed in duplicates with QuantiTect SYBR Green PCR Kit (Qiagen). All primers were purchased from Qiagen. Data were collected and analyzed, using $2^{-\Delta \Delta t}$ method for quantification of the relative mRNA expression levels. Values of genes were first normalized against $\alpha$-tubulin, and then compared to the experimental controls.

\section{Cell counting kit-8 (CCK-8) assay}

The CCK-8 detection kit (Sigma-Aldrich) was used to measure cell viability according to the manufacturer's instructions. Briefly, cells were seeded in a 96-well microplate at a density of $5 \times 10^{4} / \mathrm{ml}$. After $24 \mathrm{~h}$, cells were treated with resveratrol. Subsequently, CCK- 8 solution $(20 \mathrm{ml} /$ well $)$ was added and the plate was incubated at $37^{\circ} \mathrm{C}$ for $2 \mathrm{~h}$. The viable cells were counted by absorbance measurements with a monochromator microplate reader at a wavelength of $450 \mathrm{~nm}$. The optical density value was reported as the percentage of cell viability in relation to the control group (set as $100 \%$ ).

\section{MTT assay}

For assay of cell growth, $5 \times 10^{3}$ cell per well were seeded into 96 well-plate and subjected to a Cell Proliferation Kit (MTT, Roche, Indianapolis, IN, USA), according to the instruction of the manufacturer. The MTT assay is a colorimetric assay for assessing viable cell number, taking advantage that NADPH-dependent cellular oxidoreductase enzymes in viable cells reduce the tetrazolium dye 3-(4, 5-dimethylthiazol-2-yl)-2, 5-diphenyltetrazolium bromide (MTT) to its insoluble formazan in purple readily being quantified by absorbance value (OD) at $570 \mathrm{~nm}$ in a microtiter plate reader (Promega, Fitchburg, WI, USA). Experiments were performed 5 times.

\section{Proliferation assay}

For analysis of apoptosis, cultured cells were dissociated and re-suspended at a density of $10^{6}$ cells/ $\mathrm{ml}$ in PBS. After staining with FITC-conjugated BrdU antibody (FITC BrdU Flow Kit, Becton-Dickinson Biosciences), cells were analyzed using FACScan flow cytometer (Becton-Dickinson Biosciences) equipped with Cell Quest software (Becton-Dickinson Biosciences) for determination of FITC+ S-phase proliferating cells.

\section{Apoptosis assay}

For analysis of cell proliferation, cultured cells were dissociated and re-suspended at a density of $10^{6}$ cells $/ \mathrm{ml}$ in PBS. After double staining with FITC-Annexin V and propidium iodide (PI) from a FITC Annexin V Apoptosis Detection Kit I (Becton-Dickinson Biosciences, San Jose, CA, USA), cells were analyzed using FACScan flow cytometer (Becton-Dickinson Biosciences) equipped with Cell Quest software (BectonDickinson Biosciences) for determination of Annexin V+ PI- apoptotic cells.

\section{Western blot}

Total Protein was extracted from the patients' specimens or cultured cells by RIPA buffer (SigmaAldrich). Equal amount of proteins was loaded in the gel. Primary antibodies for Western Blot are rabbit anti-MET (detection of MET total protein) and anti- $\alpha$-tubulin (all purchased from Cell Signaling, St Jose, LA, USA). Secondary antibody is HRP-conjugated anti-rabbit (Jackson ImmunoResearch Labs, West Grove, PA, USA). The protein levels were first normalized to $\alpha$-tubulin, and then normalized to control. Images shown in the figure were representatives from 3 repeats. Densitometry of Western blots was quantified with NIH ImageJ software (Bethesda, MA, USA).

\section{Statistical analysis}

All statistical analyses were carried out using the SPSS 18.0 statistical software package. All values in cell and animal studies are depicted as mean \pm standard deviation and are considered significant if $p<0.05$. All data were statistically analyzed using one-way ANOVA with a Bonferroni correction, followed by Fisher' Exact Test for comparison of two groups. Patients' survival was determined by Kaplan-Meier analysis. 


\section{Results}

Low miR-3666 levels in TC specimens associate with poor prognosis

The levels of MET and miR-3666 in 25 pairs of TC tissues and matched tumor-adjacent normal thyroid tissues (NT) were measured by Western blot and RT-qPCR, respectively. We found that TC specimens contained significantly higher levels of MET (Fig. 1A), and significantly lower levels of miR-3666, shown by individual values (Fig. 1B), and by mean \pm SD (Fig. 1C). To examine the clinical significance of low miR-3666 levels in TC, the 25 TC patients were followed-up for 30 months. The median value of all 25 cases was chosen as the cutoff point for separating miR-3666 high-expression cases $(n=13)$ from miR-3666 lowexpression cases ( $\mathrm{n}=12)$. Kaplan-Meier curves indicated that TC patients with low miR-3666 levels had a significantly worse prognosis than those with low miR-3666 levels (Fig. 1D).

\section{Overexpression of miR-3666 inhibits TC cell growth}

Next the role of miR-3666 in the growth of cultured TC cells was investigated. We used a human TC cell line, TT, and transfected TT cells with miR-3666 mimics (miR-3666), or antisense for miR-3666 (as-miR-3666), or a control null sequence as a control (null). The levels of miR-3666 in these modified TT cells were assayed by RT-qPCR, 72 hours after transfection. We found that the miR-3666 levels in TT cells significantly increased by miR3666, while the miR-3666 levels in TT cells significantly decreased by miR-3666 suppression (Fig. 2A). The cell survival and growth were then assayed by CCK-8 assay and by MTT assay, respectively. We found that the survival of TT cells was not affected by miR-3666 modification (Fig. 2B). However, overexpression of miR-3666 significantly inhibited the cellular growth in

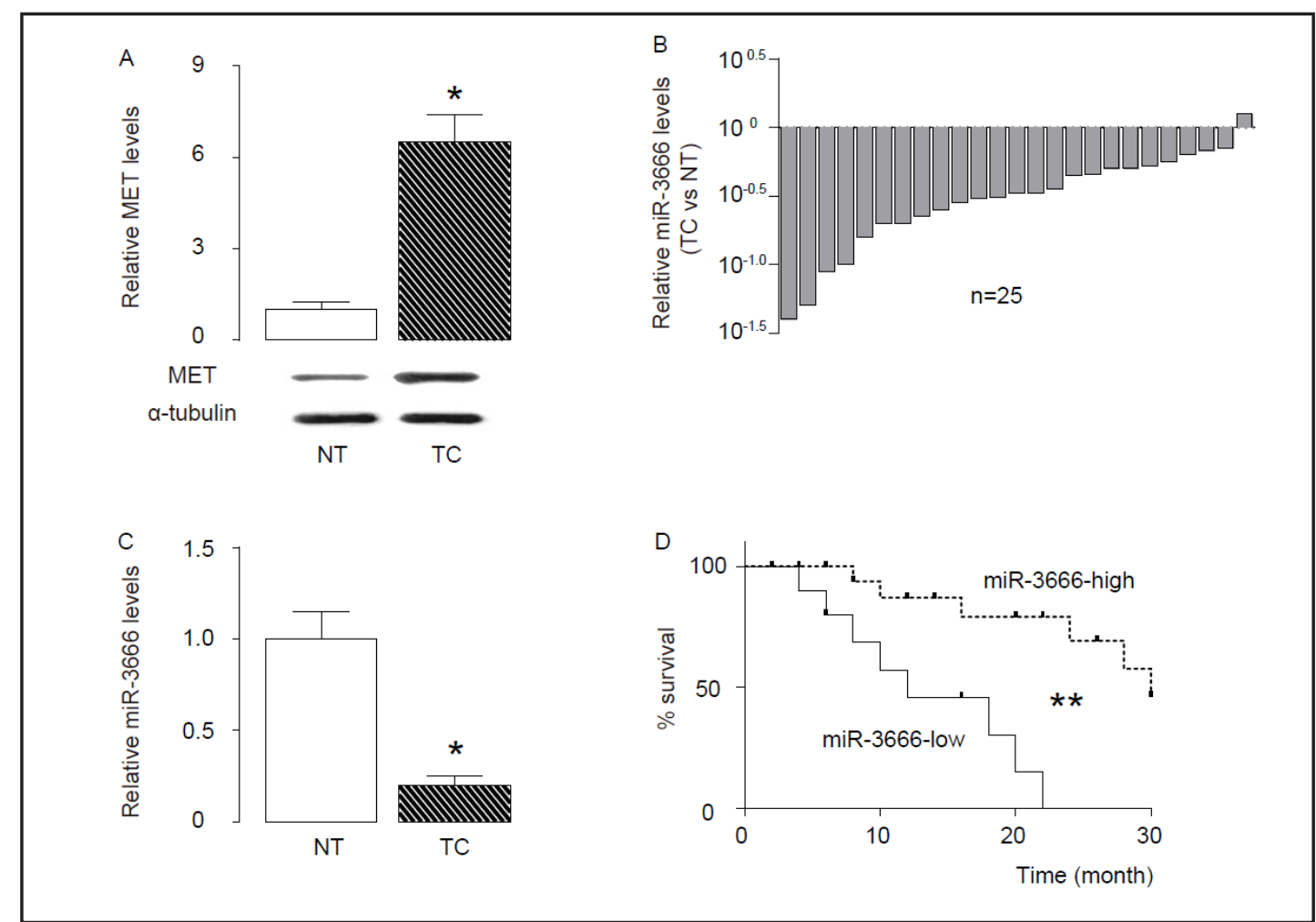

Fig. 1. Low miR-3666 level in TC tissues associates with poor survival. (A) The levels of MET in 25 TC tissues and matched tumor-adjacent normal tissue (NT) by Western blot. (B-C) The levels of miR-3666 in 25 TC tissues and matched NT by RT-qPCR, shown by individual values (B), and by mean \pm SD (C). (D) The 25 TC patients were followed-up for 30 months. The median value of all 25 cases was chosen as the cutoff point for separating miR-3666 high-expression cases $(n=13)$ from miR-3666 low-expression cases $(n=12)$. Kaplan-Meier curves were shown. ${ }^{*} \mathrm{p}<0.05{ }^{* *} \mathrm{p}<0.01 . \mathrm{N}=25$.

\section{KARGER}



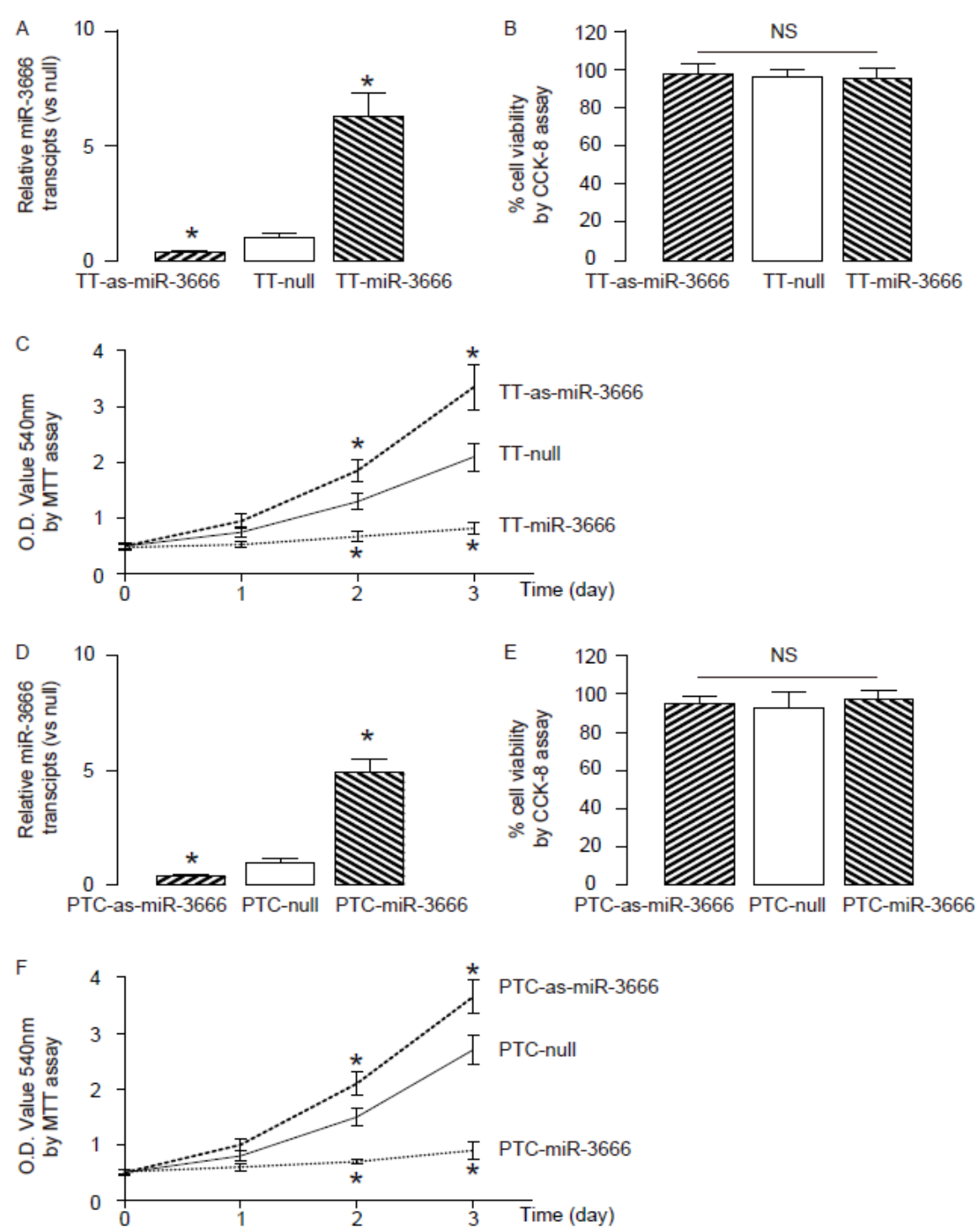

Fig. 2. Overexpression of miR-3666 inhibits TC cell growth. We transfected TT and PTC cells with miR-3666 mimics (miR-3666), or antisense for miR-3666 (as-miR-3666), or a control null sequence (null). (A) The levels of miR-3666 transcripts in miR-3666-modified TT cells were assayed by RT-qPCR, 72 hours after transfection. (B) The TT cell survival was assayed by CCK-8 assay. (C) The TT cell growth was assayed by MTT assay. (D) The levels of miR-3666 transcripts in miR-3666-modified PTC cells were assayed by RT-qPCR, 72 hours after transfection. (E) The PTC cell survival was assayed by CCK-8 assay. (F) The PTC cell growth was assayed by MTT assay. ${ }^{*} \mathrm{p}<0.05$. NS: non-significant. $\mathrm{N}=5$.

TT cells, while inhibition of miR-3666 significantly increased the cellular growth in TT cells, in an MTT assay (Fig. 2C). Similar results were obtained from another human TC cell line, PTC (Fig. 2D-F). Thus, miR-3666 inhibits TC cell growth.

TC cell apoptosis is not regulated by miR-3666

To determine whether the inhibition of TC cell growth by miR-3666 is through modulation of cell apoptosis or cell proliferation, we first analyzed cell apoptosis. By flow cytometry-based analysis, we did not detect significant alterations in apoptotic cell number/ percentage by miR-3666 in TT cells, shown by quantification (Fig. 3A), and by representative 
Fig. 3. Levels of miR-3666 does not affect TC cell apoptosis. (A-B) Cell apoptosis was analyzed by flow cytometry in miR-3666-modified TT cells, shown by quantification (A), and by representative flow charts (B). (C-D) Cell apoptosis was analyzed by flow cytometry in miR-3666-modified PTC cells, shown by quantification (C), and by representative flow charts (D). NS: non-significant. $\mathrm{N}=5$.

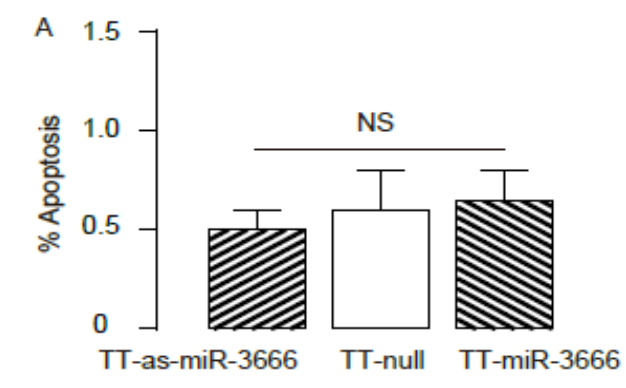

B

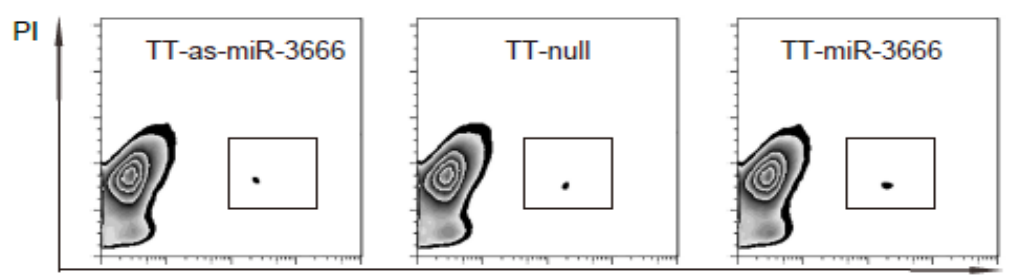

Annexin $\mathrm{V}$

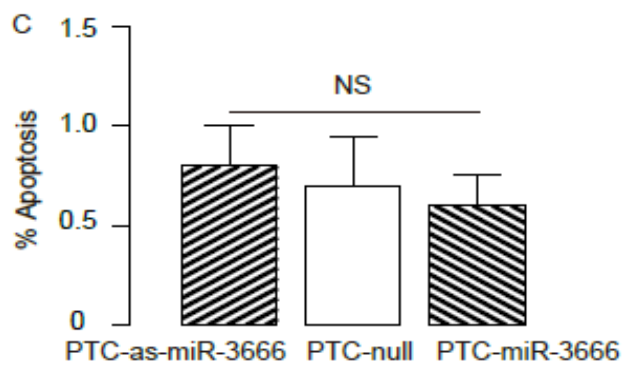

D
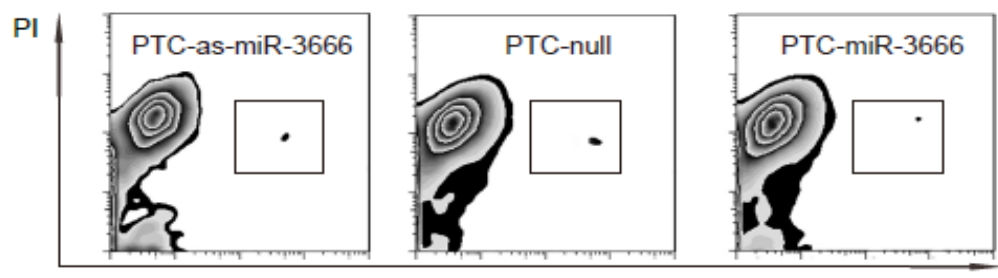

Annexin V

flow charts (Fig. 3B). Similar results were obtained from another human TC cell line, PTC (Fig. 3C-D). Hence, miR-3666 does not regulate TC cell apoptosis.

TC cell proliferation is regulated by miR-3666

To determine whether miR-3666 may inhibit TC cell growth through modulation of cell proliferation, we analyzed proliferating S-phase cells based on BrdU incorporation. We found that overexpression of miR-3666 significantly inhibited TT cell proliferation, while inhibition of miR-3666 significantly increased TC cell proliferation, shown by quantification (Fig. 4A), and by representative flow charts (Fig. 4B). Similar results were obtained from another human TC cell line, PTC (Fig. 4C-D). Hence, miR-3666 inhibits TC cell growth through suppressing cell proliferation.

MiR-3666 targets MET to regulate TC cell proliferation

Next, we predicted the potential targeted genes of miR-3666 by bioinformatics algorithms. Among all predicted genes, the tyrosine kinase MET is the receptor of the growth 
Fig. 4. Levels of miR-3666 regulate TC cell proliferation. (A-B) Cell proliferation was analyzed by flow cytometry in miR-3666-modified TT cells, shown by quantification (A), and by representative flow charts (B). (C-D) Cell proliferation was analyzed by flow cytometry in miR-3666-modified PTC cells, shown by quantification (C), and by representative flow charts (D). * $\mathrm{p}<0.05 . \mathrm{N}=5$.

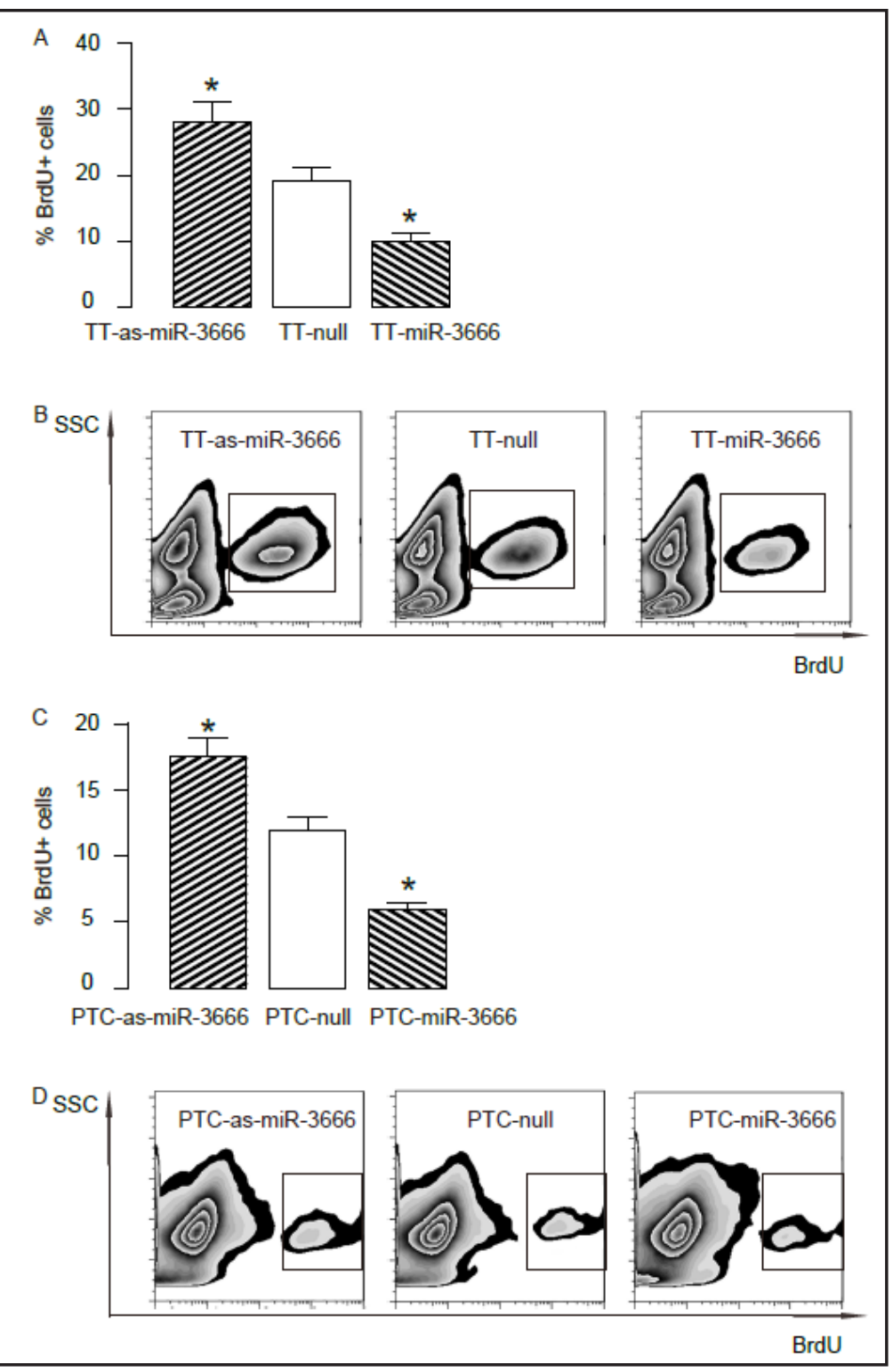

and motility factor HGF, and MET have a causal role in cell survival and growth. The 3'-UTR of MET mRNA was found to be a target for miR-3666 (Fig. 5A). The intact 3'-UTR of MET mRNA, together with a 3'-UTR with mutant at miR-3666-binding site of MET mRNA, was then cloned into luciferase reporter plasmids, and used for co-transfection with miR-3666modified plasmids into TT cells. The luciferase activities were quantified in these cells, suggesting that miR-3666 specifically targets 3'-UTR of MET mRNA to inhibit its translation (Fig. 5B).

MiR-3666 decreases MET protein but not mRNA

We then evaluated the effects of miR-3666 on MET levels in TC cells. We found that although the MET transcripts did not change by miR-3666 levels (Fig. 6A), the protein levels of MET in miR-3666-overexpressing TT cells was significantly decreased, while the protein levels of MET in miR-3666-depleted TT cells was significantly increased (Fig. 6B). Similar results were obtained from another human TC cell line, PTC (Fig. 6C-D). These data suggest that the translation of MET in TT cells is suppressed by miR-3666. Together, our study demonstrates a role of miR-3666 in control of TC cell proliferation, through MET modulation (Fig. 7). 
Fig. 5. MiR-3666 targets MET to regulate TC cell proliferation. (A) Bioinformatics algorithms analysis shows that the 3'-UTR of MET mRNA is a target for miR-3666. (B) The intact 3'-UTR of MET mRNA, together with a 3'-UTR with mutant at miR-3666-binding site of MET mRNA, was then cloned into luciferase reporter plasmids, and used for co-transfection with miR-3666-modified plasmids into TT cells. The luciferase activities were quantified in these cells. $* \mathrm{p}<0.05$. NS: non-significant. $\mathrm{N}=5$.

Fig. 6. MiR-3666 decreases MET protein but not mRNA. (A-B) We then evaluated the effects of miR-3666 on MET levels in TT cells, by mRNA (A), and by Western blot (B). (C-D) We then evaluated the effects of miR-3666 on MET levels in PTC cells, by mRNA (C), and by Western blot (D). * $\mathrm{p}<$ 0.05 . NS: non-significant. $\mathrm{N}=5$.

\section{Discussion}

Many miRNAs have been suggested to play important roles in the carcinogenesis in various cancers. However, their participation in the TC progression is surprisingly much less investigated. Indeed, elucidation of the aberrant expression of miRNAs in TC carcinogenesis will help physician and tumor biologists to better characterize the molecular regulation of the tumorigenesis of TC and may allow them to identify novel targets to improve the levels of the current therapy [22].
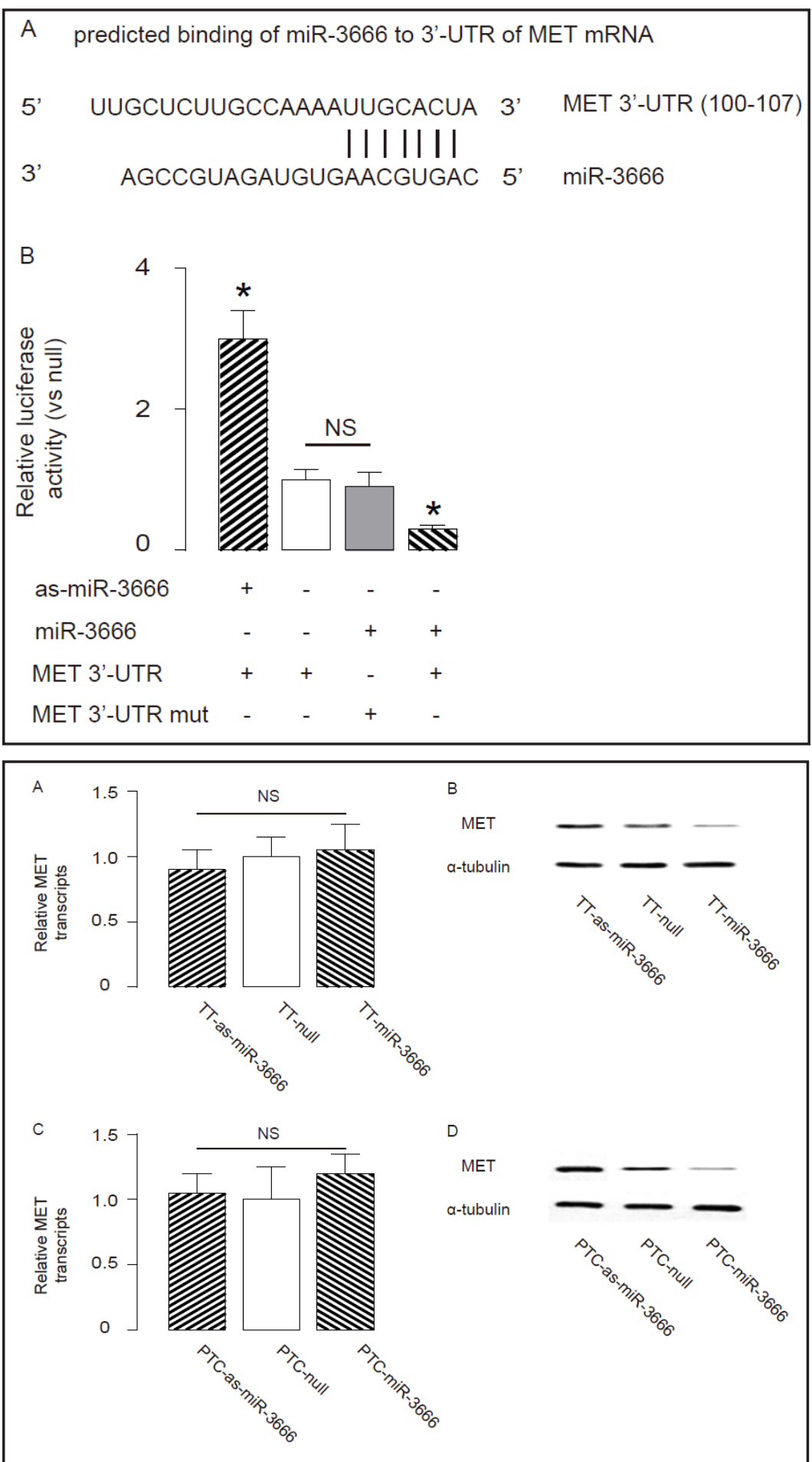


\section{Cellular Physiology Cell Physiol Biochem 2016;38:1030-1039 \begin{tabular}{l|l} 
and Biochemistry & DOI: 10.1159/000443054 \\
Published online: March 04, 2016 & $\begin{array}{l}\text { C } 2016 \text { The Author(s). Published by S. Karger AG, Basel } \\
\text { www.karger.com/cpb }\end{array}$
\end{tabular} \\ Wang/Cai/Chen: MiR-3666 Inhibits TC Growth via MET}

Fig. 7. A schematic model. MiR-3666 regulates TC cell proliferation, through translational suppression of MET.

In this study, we showed that low level of miR-3666 in TC tissues were both associated with low survival rate in TC patients. Then, we showed that miR-3666 levels negatively regulated the cell growth in 2 commonly used TC cell lines, through cell proliferation suppression, rather than through interference with cell apoptosis.

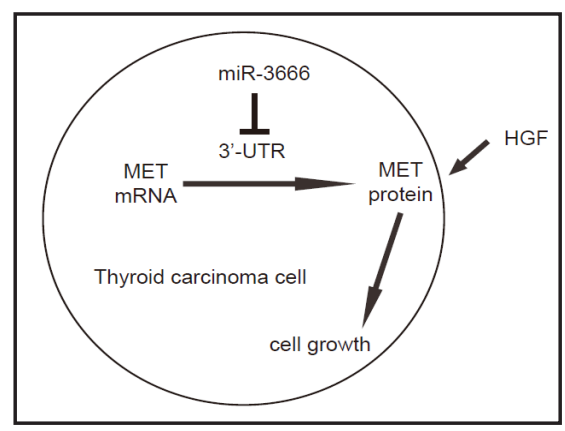

Next, we examined how cell growth may be regulated by miR-3666 levels in TC cells. Since the changes in cell number may result from a summary of cell death and cell replication, and since the signal transductions that regulate these cell death and proliferation involve a variety of key components, e.g. MET, SMADs and $\beta$-catenin, Bcl-2, Bid and Caspase 9, among which only MET was found to be a target for miR-3666, we just focused on MET in our study. Specifically, we found that the 3'-UTR of MET mRNA was targeted by miR-3666, suggesting a strong effect on the translational regulation of MET mRNA by miR-3666. Moreover, we further proved that the binding of miR-3666 to the mRNA of MET is functional in TT cells, in which it suppressed the protein level, but not mRNA level, consistent with the structural analyses. Of note, when a miRNA molecule is attached as a perfect match to a target mRNA, it causes the mRNA degradation, resulting in a decrease in mRNA levels [17-21]. Here, it appears that there is a partial interaction between the miRNA3666 and the 3'-UTR of the MET mRNA. Thus, the miRNA does not form a perfect match with the target mRNA. Therefore the translation process stops at that point and hence the protein production is reduced, as described here. Apart from effects of MET on cell growth, it may also affect cell invasiveness. We did not examine cell invasion in the current study. Besides regulation of MET by miRNA, MET protein levels may be also affected by modulation of its degradation, e.g. through ubiquitination. In future, it may be interesting to address these questions.

However, in TC, the levels of miR-3666 appeared to be undetectable. Hence, miR-3666 may be a specific regulator of the tumor cell growth in TC, and its loss may allow the tumor to grow. Further studies may address the molecular mechanisms underlying activation of miR-3666 in TC, and these approaches may provide additional evidence for using miR-3666 as a novel target for treating TC.

\section{Disclosure Statement}

The authors have declared that no competing interests exist.

\section{References}

1 Zhang J, Wang Y, Li D, Jing S: Notch and tgf-beta/smad3 pathways are involved in the interaction between cancer cells and cancer-associated fibroblasts in papillary thyroid carcinoma. Tumour Biol 2014;35:379385.

2 Chen J, Liu C, Yin L, Zhang W: The tumor-promoting function of ecrg4 in papillary thyroid carcinoma and its related mechanism. Tumour Biol 2015;36:1081-1089.

3 Deng X, Wu B, Xiao K, Kang J, Xie J, Zhang X, Fan Y: Mir-146b-5p promotes metastasis and induces epithelial-mesenchymal transition in thyroid cancer by targeting znrf3. Cell Physiol Biochem 2015;35:7182.

4 Ulbrich C, Pietsch J, Grosse J, Wehland M, Schulz H, Saar K, Hubner N, Hauslage J, Hemmersbach R, Braun M, van Loon J, Vagt N, Egli M, Richter P, Einspanier R, Sharbati S, Baltz T, Infanger M, Ma X, Grimm D: Differential gene regulation under altered gravity conditions in follicular thyroid cancer cells: Relationship between the extracellular matrix and the cytoskeleton. Cell Physiol Biochem 2011;28:185-198. 


\section{Cellular Physiology Cell Physiol Biochem 2016;38:1030-1039 \begin{tabular}{l|l} 
and Biochemistry Published online: March 04, 2016 & $\begin{array}{l}\text { C) 2016 The Author(s). Published by S. Karger AG, Basel } \\
\text { www.karger.com/cpb }\end{array}$ \\
\hline
\end{tabular} \\ Wang/Cai/Chen: MiR-3666 Inhibits TC Growth via MET}

5 Wang F, Wang P, Wang B, Fu ZJ, Yuan Y, Yan SL, Zhao WJ, Wang YG: Association between tp53 arg72pro polymorphism and thyroid carcinoma risk. Tumour Biol 2014;35:2723-2728.

6 Wang H, Li YP, Chen JH, Yuan SF, Wang L, Zhang JL, Yao Q Li NL, Bian JF, Fan J, Yi J, Ling R: Prognostic significance of usp22 as an oncogene in papillary thyroid carcinoma. Tumour Biol 2013;34:1635-1639.

7 Wan L, Zhu L, Xu J, Lu B, Yang Y, Liu F, Wang Z: Microrna-409-3p functions as a tumor suppressor in human lung adenocarcinoma by targeting c-met. Cell Physiol Biochem 2014;34:1273-1290.

8 Trusolino L, Bertotti A, Comoglio PM: Met signalling: Principles and functions in development, organ regeneration and cancer. Nat Rev Mol Cell Biol 2010;11:834-848.

9 Garouniatis A, Zizi-Sermpetzoglou A, Rizos S, Kostakis A, Nikiteas N, Papavassiliou AG: Vascular endothelial growth factor receptors 1,3 and caveolin-1 are implicated in colorectal cancer aggressiveness and prognosis--correlations with epidermal growth factor receptor, cd44v6, focal adhesion kinase, and c-met. Tumour Biol 2013;34:2109-2117.

10 Liu H, Qian C, Shen Z: Anti-tumor activity of oridonin on snu-5 subcutaneous xenograft model via regulation of c-met pathway. Tumour Biol 2014;35:9139-9146.

11 Huang J, Dong B, Zhang J, Kong W, Chen Y, Xue W, Liu D, Huang Y: Mir-199a-3p inhibits hepatocyte growth factor/c-met signaling in renal cancer carcinoma. Tumour Biol 2014;35:5833-5843.

12 Samadi AK, Cohen SM, Mukerji R, Chaguturu V, Zhang X, Timmermann BN, Cohen MS, Person EA: Natural withanolide withaferin a induces apoptosis in uveal melanoma cells by suppression of akt and c-met activation. Tumour Biol 2012;33:1179-1189.

13 Li Y, Zhang S, Tang Z, Chen J, Kong W: Silencing of c-met by rna interference inhibits the survival, proliferation, and invasion of nasopharyngeal carcinoma cells. Tumour Biol 2011;32:1217-1224.

14 Grabellus F, Konik MJ, Worm K, Sheu SY, van de Nes JA, Bauer S, Paulus W, Egensperger R, Schmid KW: Met overexpressing chordomas frequently exhibit polysomy of chromosome 7 but no met activation through sarcoma-specific gene fusions. Tumour Biol 2010;31:157-163.

15 Koo BS, Kim JM, Seo ST, Yoon YH, Kwon KR, Kim SH, Kwon HW, Bae WJ, Lim YC: Upregulation of hgf and c-met is associated with subclinical central lymph node metastasis in papillary thyroid microcarcinoma. Ann Surg Oncol 2014;21:2310-2317.

16 Bentzien F, Zuzow M, Heald N, Gibson A, Shi Y, Goon L, Yu P, Engst S, Zhang W, Huang D, Zhao L, Vysotskaia V, Chu F, Bautista R, Cancilla B, Lamb P, Joly AH, Yakes FM: In vitro and in vivo activity of cabozantinib (xl184), an inhibitor of ret, met, and vegfr2, in a model of medullary thyroid cancer. Thyroid 2013;23:15691577.

17 Di Leva G, Croce CM: Mirna profiling of cancer. Curr Opin Genet Dev 2013;23:3-11.

18 Pereira DM, Rodrigues PM, Borralho PM, Rodrigues CM: Delivering the promise of mirna cancer therapeutics. Drug Discov Today 2013;18:282-289.

19 Mei Q, Li F, Quan H, Liu Y, Xu H: Busulfan inhibits growth of human osteosarcoma through mir-200 family micrornas in vitro and in vivo. Cancer Sci 2014;105:755-762.

20 Wang F, Xiao W, Sun J, Han D, Zhu Y: Mirna-181c inhibits egfr-signaling-dependent mmp9 activation via suppressing akt phosphorylation in glioblastoma. Tumour Biol 2014;35:8653-8658.

21 Liu G, Jiang C, Li D, Wang R, Wang W: Mirna-34a inhibits egfr-signaling-dependent mmp7 activation in gastric cancer. Tumour Biol 2014;35:9801-9806.

22 Behr TM, Wulst E, Radetzky S, Blumenthal RD, Dunn RM, Gratz S, Rave-Frank M, Schmidberger H, Raue F, Becker W: Improved treatment of medullary thyroid cancer in a nude mouse model by combined radioimmunochemotherapy: Doxorubicin potentiates the therapeutic efficacy of radiolabeled antibodies in a radioresistant tumor type. Cancer Res 1997;57:5309-5319.

23 Kondo T, Ezzat S, Asa SL: Pathogenetic mechanisms in thyroid follicular-cell neoplasia. Nat Rev Cancer 2006;6:292-306.

24 Coronnello C, Benos PV: Comir: Combinatorial microrna target prediction tool. Nucleic Acids Res 2013;41:W159-164. 